\title{
Novos liberalismos e a Grande \\ Recessão: princípios para uma política externa crítica
}

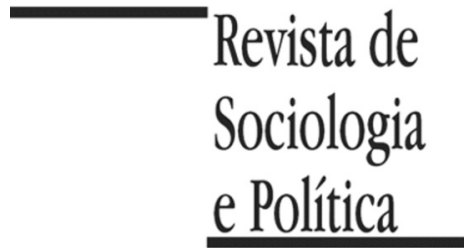

DOI: $10.1590 / 1678-987314225008$

\author{
Igor Abdalla
}

\begin{abstract}
RESUMO
O artigo analisa a emergência, nas últimas décadas, de novo liberalismo internacionalista de cunho tecnocrático, que se divorcia do liberalismo clássico criado pelo filósofo crítico Immanuel Kant. O novo liberalismo, que coincide com o processo de globalização das finanças, inverte o elemento emancipatório do liberalismo kantiano para apresentar-se como instância de ratificação do poder. Como resultado, os novos liberais são incapazes de analisar criticamente eventos como a Grande Recessão. Em contraposição ao novo liberalismo tecnocrático propõem-se princípios para uma política externa crítica para o Brasil. Em termos empíricos, escrutinase a evolução do processo de globalização das finanças do ponto de vista do poder, com enfoque sobre as crises financeiras no mundo em desenvolvimento e a Grande Recessão de 2008. Propugnam-se os seguintes argumentos: (i) o novo liberalismo contradiz o liberalismo clássico; (ii) o novo liberalismo legitima interesses de atores hegemônicos voltados para a liberalização e a desregulamentação financeiras sem limites, que se encontram na raiz da Grande Recessão; (iii) a política externa brasileira deve resgatar elementos do liberalismo clássico no contexto de crise gerado pela Grande Recessão.
\end{abstract}

PALAVRAS-CHAVE: liberalismo internacionalista; teoria crítica; globalização; política externa brasileira; crise de 2008.

Recebido em 30 de Dezembro de 2013. Aprovado em 15 de Janeiro de 2014.

\section{Introdução ${ }^{1}$}

\footnotetext{
${ }^{1}$ Agradece-se aos pareceristas anônimos da Revista de Sociologia e Política por suas contribuições ao artigo.
}

A pós a Guerra Fria, acadêmicos como Andrew Moravcsik, Robert Keohane e Anne-Marie Slaughter capitalizam sobre a crise disciplinar gerada pela mudança de paradigma em Direito e Relações Internacionais (Kratochwil 2010, p. 120) para desenvolver novo liberalismo internacionalista tecnocrático (Koskenniemi 2001). O novo liberalismo agrava a miopia dos internacionalistas quanto aos efeitos do poder, sustentando visão de mundo na qual a economia preexiste à política e esta preexiste ao Direito (Kennedy 2004, p. 19). Assim, a economia global nunca é problematizada, a política é reduzida a questões técnicas e ignora-se o papel dos Direitos brandos (Fundo Monetário Internacional, Banco Mundial) e duros (Organização Mundial do Comércio) das instituições internacionais na criação de assimetrias (Medina de Souza 2011). A atitude acrítica frente à globalização é resultado da separação entre política e a economia em RI e DI. Como observou Alston (1997), o fato de os juristas não problematizarem a estrutura da economia global tem resultado em agendas superficiais. Em RI, Smith (2004, pp. 505-506) apontou que "no mainstream, a política e a economia são áreas separadas", de forma que os acadêmicos ignoram que "de longe, a maior parte da violência no planeta é econômica na origem".

O discurso do novo liberalismo divorcia-se do liberalismo clássico criado pelo filósofo crítico Immanuel Kant. Enquanto Kant condenou as práticas comerciais desiguais dos países mais poderosos do seu tempo (Kant 1991a; Jahn 
2005), os novos liberais ignoram as assimetrias do atual regime de comércio. Apesar de a filosofia política de Kant fundar-se sobre a autonomia dos atores políticos como seres morais, liberais como Slaughter (2004) propõem "melhores práticas" que virtualmente revogam o espaço para escolhas políticas no mundo em desenvolvimento (Kratochwil 2010). Ainda que Kant (1991b) tenha condicionado o aperfeiçoamento das Nações às suas relações exteriores, os liberais contemporâneos invariavelmente culpam a política doméstica dos países em desenvolvimento pelos seus infortúnios. A Grande Recessão que eclodiu em 2008 acentuou a ascensão do Sul Global (PNUD 2013), assim como deslocou o epicentro da governança global para novos fóruns, como o G20 e o BRICS. Abrem-se possibilidades para que Nações em desenvolvimento, em especial, países em ascensão, como o Brasil - persigam uma política externa crítica, resgatando o elemento emancipatório do liberalismo kantiano, em contraposição aos novos liberais.

Ao descrever a emergência do novo liberalismo em RI e DI, na próxima seção, expõe-se como os novos liberais negligenciam as assimetrias inerentes à globalização. Argumenta-se que a globalização financeira foi resultado da mobilização maciça de poder por uma constelação de forças hegemônicas que condicionou a visão de mundo dos técnicos em política econômica. Estuda-se, na seção seguinte, as crises financeiras nos países emergentes com base no caso emblemático da Argentina, indicando-se como a adoção dogmática do receituário dominante do novo liberalismo econômico criou "viseiras ideológicas" (Tenembaum 2004) que impediram o estancamento da crise. Discorre-se, na seção final, sobre a Grande Recessão como ponto culminante da liberalização e desregulamentação financeiras sem limites das últimas décadas e propõem-se princípios - afinados ao kantianismo, em contraposição ao novo liberalismo tecnocrático, para a política externa brasileira, no contexto de crise gerado pela Grande Recessão.

\section{O Novo Liberalismo Internacionalista Tecnocrático}

Em sequência à edição especial do periódico International Organization sobre regimes internacionais em 1982, que uniu teóricos realistas e liberais, Robert Keohane lançou as bases da teoria institucionalista neoliberal na influente obra After Hegemony (Keohane 1984). Keohane apagou estrategicamente a dicotomia conflito-cooperação ao propor que a harmonia de interesses torna a cooperação e as instituições desnecessárias, donde conclui-se que a cooperação tem lugar à sombra do conflito. As instituições, ao reduzirem os custos de transação e a assimetria de informações, permitiriam aos Estados passarem de equilíbrios sub-ótimos a situações eficientes no sentido de Pareto (idem). Institucionalistas como Arthur Stein aprofundaram a síntese entre realistas e liberais. Nas palavras de Stein (1990, p. 12): "relações internacionais envolvem cooperação e conflito, mais cooperação do que os realistas admitem e mais conflito do que os liberais reconhecem". O institucionalismo não somente deixava de problematizar a globalização que emergia, mas também racionalizava a ordem pós-1945 ao apontar a sua "desejabilidade" geral, em momento no qual se acreditava haver declínio da hegemonia dos EUA. Esse pano de fundo normativo enviesava o institucionalismo na direção da manutenção da ordem em detrimento de outros objetivos, como a justiça distributiva.

Mais fundamentalmente, o institucionalismo consagrava a visão tipicamente liberal de que instituições internacionais e governança global produzem ganhos a todos os atores envolvidos. Embora Andrew Moravcsik tenha poste- 
${ }^{2}$ A referência, de 2005, é uma edição mais recente de After Hegemony, com um novo prefácio. (NR). riormente aperfeiçoado a visão liberal das instituições ao incluir a ação de grupos de interesse em seu estudo inovador sobre a integração europeia, as instituições ainda assim levam a melhoras de Pareto (Moravcsik 1998, pp. 6-9). Como admitiu o próprio Keohane ${ }^{2}$ (2005, p. xi; Kratochwil \& Ruggie 1986, p. 769), o institucionalismo espelhava-se na experiência do regime de comércio do GATT (acrônimo em língua inglesa para General Agreement on Tariffs and Trade), criado em 1947. Embora a elaboração do institucionalismo tenha coincidido com a transformação do GATT 1947 na Organização Mundial do Comércio durante a Rodada Uruguai (1986-1994), não se investigam os flagrantes desequilíbrios do arcabouço normativo da OMC. As assimetrias criadas pela OMC na esfera econômica, de fato, nunca são problematizadas pelos teóricos liberais e a política é reduzida a questões operacionais, como que tipo de reformas devem ser implementadas no Entendimento para a Solução de Controvérsias (Goldstein \& Martin 2000; Petersmann 1997; Slaughter 2000).

O acordo que estabelece a OMC traz liberalização mínima ou nula em agricultura (Hathway \& Ingco 1995), área na qual os países em desenvolvimento são mais competitivos e a única na qual persistem "megatarifas" e subsídios às exportações. Apenas os subsídios para o algodão nos EUA reduzem entre 1$2 \%$ o PIB de países africanos como o Benin (Charlton \& Stiglitz 2005, p. 62). Com a Rodada Doha longe de ser completada, quase 50\% do orçamento da União Europeia ainda é gasto com a Política Agrícola Comum (PAC). O arcabouço normativo da OMC foi moldado por negociações entre os Estados Unidos e a União Europeia, que impuseram aos países em desenvolvimento escolha entre aderir à nova organização ou perder o acesso aos dois maiores mercados do planeta (Medina de Souza 2013; Steinberg 2002). Há consistente evidência de que a OMC trouxe perdas a países da África, em frontal contradição ao institucionalismo. Estudos apontam perdas absolutas para a África em termos de PIB e exportações (Charlton \& Stiglitz 2005; Harrison, Rutherford \& Tarr 1994; Hathway \& Ingco 1995), medidas de bem-estar econômico (Davenport \& Page 1994, p. 63), assim como vultosos custos de implementação (Finger \& Schuler 2000, p. 511). Deve-se destacar, ainda, que nenhum país africano jamais iniciou uma disputa na OMC.

A consolidação definitiva da globalização, em substituição ao paradigma da Guerra Fria, abriu espaço para ataques mais ambiciosos à teoria realista de RI por parte de teóricos liberais como Andrew Moravcsik. Moravcsik (1997) propõe uma nova versão da teoria liberal cuja premissa é que "os atores fundamentais da política internacional são indivíduos e grupos privados" em um mundo no qual a soberania está em declínio, pois "o Estado não é um ator, mas uma instituição representativa, constantemente sujeita a captura e recaptura" (idem, p. 518). O enfoque sobre a política doméstica é uma constante entre os novos liberais, que distinguem Estados entre liberais e não liberais e culpam fatores domésticos pelas mazelas que afetam os últimos (Doyle 1983; Moravcsik 1997; Slaughter 1995; Rawls 1999). Acadêmica com formação em DI e RI, Anne-Marie Slaughter, que ocupou posições de relevo, incluindo a de Secretária de Planejamento Diplomático do governo Obama, é a maior expoente na promoção de estudos interdisciplinares liberais. Em importante artigo para o debate interdisciplinar, Slaughter (1993) propôs a "agenda dual" contemplando o institucionalismo e a teoria liberal de Moravcsik como plataformas de cooperação DI/RI.

A agenda dual concretizou-se, na prática, quando Moravcsik e Slaughter juntaram-se a teóricos institucionalistas, entre os quais Robert Keohane, na edição especial da International Organization dedicada à "legalização" da po- 
lítica internacional, em 2000. O conceito de "legalização", derivado da teoria legal de H.H. Hart e que se subdividia nas dimensões da obrigação, da precisão e da delegação, foi empregado para caracterizar regimes entre os extremos do Direito duro e da anarquia. A visão empobrecida do Direito, contudo, exageradamente concentrada em tratados e resoluções de disputas impede compreensão mais acurada do seu papel constitutivo, por exemplo, na atribuição de direitos de propriedade (Finnemore \& Toope 2001). Embora o Acordo sobre Aspectos dos Direitos de Propriedade Intelectual Relacionados ao Comércio (TRIPS, no acrônimo em língua inglesa) seja considerado uma instância de alta legalização (Abbott et al. 2000), os teóricos liberais não lidam com suas consequências distributivas. O TRIPS acarreta pagamentos de países em desenvolvimento, somente aos EUA, da ordem de US\$ 5,8 bilhões anuais (Maskus 2000, p. 142), assim como aumenta preços de bens essenciais como produtos farmacêuticos em países pobres, o que causou ultraje global no contexto da luta contra o HIV-AIDS na África do Sul.

Mais recentemente, Moravcsik propôs que "a condição universal da política mundial é a globalização" (2008, p. 234; grifo no original). A ordem econômica, entretanto, é um dado da realidade no sentido de que não se investigam os efeitos distributivos da globalização, que é reduzida ontologicamente à mera fonte de incentivos e constrangimentos. Ao incorporar a teoria liberal de Moravcsik, a proposta interdisciplinar de Slaughter agrava os vieses normativos e analíticos dos internacionalistas liberais, que incorporam o Direito ou a política que é eivado(a) com as mesmas premissas que impedem o escrutínio das relações de poder subjacentes à economia global (Kennedy 1999, pp. 104-105). De maneira similar ao conceito de "teoria de resolução de problemas" formulado em Cox (1981), o jurista Martti Koskenniemi (2001, p. 440) caracteriza o novo liberalismo como "tecnocrático" (managerialist). Como o autor afirmou, "a proposta de estudos interdisciplinares não pode ser dissociada dos tipos de sociologia e ética que são advogados", porque "a sociologia é sempre carregada normativamente, e carregada de forma a subscrever uma constelação produzida anteriormente pelo poder" (Koskenniemi 2001, pp. 448-449).

Os esforços teóricos próprios de Slaughter, que também se destacou, desde a década de 1990, pelo desenvolvimento de uma nova teoria liberal em DI (Slaughter 1995), foram direcionados, mais recentemente, a uma abordagem tecnocrática do Direito. A "nova ordem mundial" de Slaughter $(1997 ; 2004)$ é marcada por sistema de governança global no qual o Estado se desagrega em redes de técnicos, que difundem "melhores práticas" por todo o mundo. A visão tecnocrática do Direito é visível quando melhores práticas" assumem caráter de neutralidade e universalidade. Conforme asseverou Kennedy (2001, pp. 93-94), a noção de "melhores práticas" invoca associação com "necessidade prática e eficiência em lugar de posições políticas e distribuição", de forma que "agentes da política na esfera internacional falam muito mais da 'melhor' política ou prática que de vencedores e perdedores". Kennedy (idem, p. 68) acrescenta que os agentes da política internacional "aspiram à inoculação contra a quebra de ovos que acompanha toda governança e governo, porque simplesmente não há política que não distribua. Nesse sentido, a governança internacional é um exercício de poder".

Slaughter (2004, p. 19), entretanto, dá pistas sobre assimetrias quando sugere que as "melhores práticas" seriam transmitidas dos países desenvolvidos aos países em desenvolvimento, nunca em sentido contrário. Como se houvesse dúvidas quanto ao destinatário das suas prescrições, Slaughter explicita que 
Quadro 1 - Liberalização de Fluxos de Capitais

\begin{tabular}{ll}
\hline País & Liberalização dos Fluxos de Capitais \\
\hline Estados Unidos & 1974 \\
Reino Unido & 1979 \\
Austrália e Nova Zelândia & $1984-5$ \\
Membros das Comunidades Europeias & 1988 \\
Países Escandinavos & $1989-1990$ \\
Japão & Gradualmente durante os anos 1980 \\
\hline
\end{tabular}

Fonte: Helleiner (1994).

o novo sistema de governança global "seria particularmente atrativo para os Estados Unidos" (idem, pp. 4-5). Dessa forma, não surpreende que "melhores práticas" sejam, em última instância, as práticas dos EUA, ainda mais quando se considera que as práticas da potência hegemônica estão congenitamente imersas em retórica universalista (Kratochwil 2010, p. 135). Sintomático de que "melhores práticas" correspondem às práticas dos EUA é que o mais célebre conjunto de ditas medidas denomina Consenso de Washington. O Consenso de Washington, originalmente criado para os países latino-americanos nos anos 1980, expandiu seu escopo com o fim da Guerra Fria e contribuiu para completar a liberalização financeira iniciada pelos EUA e pelo Reino Unido, que buscaram capitalizar sobre vantagens competitivas no setor de finanças para abrir mercados de capitais (Helleiner 1994, p. 4).

Ao redor das diretrizes do Consenso de Washington convergiram não somente o Tesouro dos EUA, mas também o FMI e o Banco Mundial, que reverteram o keynesianismo congênito para eivar o seu Direito brando na ortodoxia do neoliberalismo econômico. O neoliberalismo econômico invocava a liberdade humana, equiparando-a à liberdade de mercado, e moldava problemas com base em mantras como "contenção de déficit" e "combate à inflação" às expensas de variáveis como nível de emprego. Em termos de política econômica, o Consenso de Washington combinava medidas de liberalização financeira, abertura comercial e austeridade fiscal. Essas diretrizes, que condicionaram a perspectiva dos técnicos em economia (Gill \& Law 1989), eram congruentes com os interesses hegemônicos, implicavam larga transferência de rendas e abriram caminho para crises especulativas ao expor os sistemas financeiros dos países em desenvolvimento aos vastos fluxos globais de capitais (Stiglitz 2003).

\section{Problematizando a Globalização: o Novo Liberalismo Econômico}

Os Estados Unidos valeram-se do seu poder estrutural nas finanças internacionais (Strange 1988) para reverter a ordem financeira restritiva de Bretton Woods (Ruggie 1982) e satisfazer as suas vantagens competitivas no setor financeiro ao promover a globalização desde a década de 1970 (Helleiner 1994). Como Helleiner (idem, p. 14) apontou, a hegemonia nas finanças internacionais "dava aos Estados Unidos uma razão fundamental para promover o processo de globalização". Os EUA e o Reino Unido perseguiram a globalização das finanças a partir de iniciativas liberalizantes, como o Euromercado baseado em Londres, e preventivas, como a criação do G10 para evitar crises de grande escala após a abertura dos mercados de capitais nos países desenvolvidos (Quadro 1). A liberalização das finanças sofreu, de fato, fortes turbulências com a crise bancária de 1974, a crise da dívida a partir de 1982 e a crise do 
mercado acionário em 1987. O impulso dos EUA para a globalização das finanças é frequentemente eclipsado pela crença apolítica de que a globalização foi criada exclusivamente por desenvolvimentos tecnológicos. Williamson (1998, pp. 2-4), o economista que cunhou a expressão Consenso de Washington, propôs, por exemplo, que a "globalização é resultado de desenvolvimentos tecnológicos e não escolhas políticas". A noção de que a globalização foi "causada" por desenvolvimentos tecnológicos naturaliza um processo essencialmente político.

Teóricos de matriz gramsciana têm analisado o papel do poder na construção da globalização. A proposição básica do ex-líder do partido comunista italiano Antonio Gramsci era que o poder da classe dominante assentava-se apenas parcialmente no Estado em si (Cox 1983, p. 163). A construção de uma ideologia dominante, expressa em termos universais, constrói o consentimento ao dar "alguma satisfação aos grupos subordinados, sem comprometer a liderança ou interesses vitais da classe hegemônica" (idem, p. 169). Quando a definição de problemas é moldada pela ideologia dominante e as políticas derivadas de suas proposições são adotadas com pouca ou nenhuma reflexão, o poder adquiriu dimensão hegemônica ou estrutural (Gill \& Law 1989, pp. 48486). Ainda que eventos como a crise financeira iniciada em 2008 levantem questões sobre a manipulação direta de técnicos de política econômica por grupos de interesses, é notoriamente difícil ligar alternativas de escolha política a interesses particulares de qualquer forma determinante. David Kennedy habilmente observou que argumentos sobre "captura" têm sido exagerados ao ponto de "deslocar investigações sobre outras fontes de vieses que podem se mostrar mais significantes" (Kennedy 2001, p. 97).

Em vez de sugerir que especialistas foram simplesmente capturados, sugere-se que eles compartilhavam uma visão de mundo congruente com o impulso da globalização das finanças mundiais desde a década de 1970. Essa é uma dimensão mais sutil, mas, ao mesmo tempo, mais profunda, em outras palavras, estrutural, em que atores domésticos e estrangeiros contribuíram para criar as condições que levaram às crises financeiras nos países emergentes e, em última instância, à Grande Recessão. Isso porque eles aplicaram de forma irrefletida e dogmática políticas de irrestrita liberalização e desregulamentação financeira. Como asseverou Claudio Loser, economista do FMI a cargo da América Latina entre 1994-2002, sobre a suposta captura do staff do Fundo pela comunidade financeira (Tenembaum 2004, p. 72): "Acredito que aconteceu outra coisa ao Fundo e em outros círculos acadêmicos de Washington. Serei bem claro sobre isso. Havia muito dogma e muito pouca atenção na forma como as coisas eram gerenciadas. Sempre que os preceitos ideológicos eram seguidos, ninguém avaliava a sua aplicação concreta. Essa atmosfera dominou não somente Washington, mas também toda a intelectualidade da América Latina, o que você chamaria de 'economistas liberais'. O modelo de abertura impulsionado por Reagan e Thatcher tinha o seu correlato na América Latina e isso ressoou em Washington, onde se formou o chamado 'Consenso de Washington'".

Seguindo essa perspectiva, uma nova hegemonia gramsciana foi construída a partir dos anos 1970, em que o keynesianismo deu lugar ao neoliberalismo econômico como nova ideologia dominante. A nova constelação hegemônica incluiu o aparato estatal dos países do G7, o capital transnacional (Gill 1995, pp. 400-401) e instituições acadêmicas de ponta. Sintomático da liderança dos EUA e do Reino Unido, os dois intelectuais orgânicos mais visíveis, os prêmios Nobel Friedrich Hayek (London School of Economics e Universidade de 
Chicago) e Milton Friedman (Universidade de Chicago), eram afiliados a universidades desses países. Suas ideias impulsionaram redes de intelectuais e a criação de instituições destinadas a influenciar a opinião pública, como a Mont Pélèrin Society e a Heritage Foundation. Estudantes promissores de países em desenvolvimento adquiriam bolsas para cursos nas universidades associadas à nova ortodoxia (Gill e Law 1989, p. 482). Como ideologia dominante, o neoliberalismo apresentava as suas credenciais universalistas na forma de uma doutrina da liberdade humana (Hayek 1944), que implicava reformulação radical das liberdades de mercado e a redução da ação governamental para evitar o comportamento autointeressado dos agentes públicos. A teoria econômica keynesiana encontrava rival à altura na teoria monetarista, que incluía uma reinterpretação das causas da Grande Depressão (Friedman \& Schwartz 1963).

Ainda que o neoliberalismo tenha sido inicialmente aplicado em países latino-americanos como o Chile e a Argentina, os dois ícones políticos neoliberais encabeçavam os governos dos EUA e do Reino Unido. De fato, a ascensão ao poder de Margaret Thatcher (1979) e Ronald Reagan (1981) é comumente apontada como o divisor de águas na concretização da pretensão hegemônica do neoliberalismo. Como consequência, o FMI e o Banco Mundial reverteram radicalmente o seu keynesianismo congênito. O Banco Mundial transcendeu o papel de provedor de empréstimos para focar empréstimos de ajustamento estrutural. Tais empréstimos eram condicionados à aprovação do FMI, que usava o poder de barganha conferido pelo seu selo de aprovação para moldar políticas no mundo em desenvolvimento. Nessa conjuntura, a convergência entre o FMI, o Banco Mundial e o governo Reagan no trato dos países endividados da América Latina deu origem ao Consenso de Washington. Como propôs Stiglitz (2003, pp. 13-16): "As mudanças mais dramáticas nessas instituições [o FMI e o Banco Mundial] ocorreram na década de 1980, a Era na qual Ronald Reagan e Margaret Thatcher pregavam a ideologia do livre mercado nos Estados Unidos e no Reino Unido. O FMI e o Banco Mundial tornaram-se as instituições missionárias, por meio das quais essas ideias eram impostas aos países pobres relutantes que, com frequência, precisavam desesperadamente dos seus empréstimos e financiamentos [...]. A orientação keynesiana do FMI, que enfatizava as falhas de mercado e o papel do governo na criação de empregos, foi substituída pelo mantra do livre mercado dos anos 1980, parte de um novo 'Consenso de Washington' - um consenso entre o FMI, o Banco Mundial e o Tesouro dos EUA sobre as políticas 'corretas' para os países em desenvolvimento".

A mais visível ruptura do FMI com o keynesianismo aconteceu na nova defesa da liberalização financeira. Como forma de proteger o então emergente estado de bem-estar social de fluxos desestabilizadores de capitais, Keynes idealizara em Bretton Woods ordem que, em suas próprias palavras, "não somente como medida de transição, mas como arranjo permanente, concede a todos os governos dos Estados membros o direito explícito de controlar todos os movimentos de capitais" (Helleiner 1994, p. 4). A nova defesa da liberalização irrestrita dos mercados de capitais refletiu a vitória, no interior da administração Clinton nos EUA, do Tesouro sobre o Conselho de Assessores Econômicos, que advertira sobre a instabilidade que a abertura financeira desmedida causaria nos países em desenvolvimento (Blustein 2003, p. 49). Como asseverou Stiglitz (2003, pp. 31-32), membro, à época, do Conselho de Assessores Econômicos, a defesa da liberalização financeira tornou-se tão dogmática que instituições como o FMI viam "um sistema financeiro liberalizado" como "um fim em si mesmo", pois "estavam tão certos da sua posição dogmá- 
tica que tinham pouco interesse em verificar experiências reais". De fato, meses após ataques especulativos em massa terem iniciado a crise financeira na Ásia, o FMI propunha reforma para formalizar a ruptura com seus fundadores em Bretton Woods, incluindo a liberalização financeira no seu Acordo Constitutivo (Blustein 2003, p. 49).

As volumosas dívidas dos países em desenvolvimento na década de 1980 conferiam poder aos detentores de ativos financeiros, habilitando-os a exercer poder estrutural à medida que podiam moldar a formulação de políticas (Gill \& Law 1989, p. 481). Como apontou Cox (1981, p. 144), estruturas são "constrangimentos à ação". Países endividados viam reduzidos seus graus de liberdade na proporção da necessidade de angariar a "confiança dos investidores", o que implicava a aceitação de um arcabouço de moldagem de problemas centrado em mantras como "combate à inflação" e cortes de despesas" (idem, pp. 484-485). Atores-chave nos países em desenvolvimento, marcadamente os economistas liberais, facilitavam a implementação das políticas neoliberais. À medida que as políticas neoliberais eram aceitas sem a consideração de cursos alternativos de ação, o poder adquiria status hegemônico. O componente consensual da hegemonia conecta-a à noção de poder estrutural, uma vez que a naturalização da ideologia dominante torna atores subordinados incapazes de reconhecer a sua própria subordinação.

\section{Argentina: epítome das crises financeiras nos países emergentes}

De acordo com Stiglitz (2010), a doutrina do "fundamentalismo de mercado" inclui não somente a implantação de modelos econômicos neoliberais, mas também a adoção de pacotes ortodoxos anticrise em momentos de turbulência. A construção do modelo neoliberal na Argentina ocorreu durante a ditadura militar (1976-1983) e o governo Menem (1989-1999) (Bonelli 2004, p. 55), ao passo que o governo De la Rúa (1999-2001) foi marcado pela aplicação do receituário ortodoxo anticrise que desembocou na catástrofe de 2001. Os números refletem a turbulência socioeconômica trazida pela hegemonia neoliberal: o PIB estagnou-se no período 1976-1999, com queda de 30\% per capita (Ferrer 2010) e o desemprego alcançou 30\% em 1999. A parcela dos 10\% mais ricos da população absorveu $36,1 \%$ da renda em 1999, comparados a 23,6\% em 1974, enquanto a parcela dos $10 \%$ mais pobres teve a sua participação reduzida de $4,4 \%$ a $1,5 \%$ no mesmo período (Rapoport 2009, p. 885). Mais de $57 \%$ da população estava na pobreza em 2002 (Ferrer 2010, pp. 439-441) e a dívida externa atingiu US\$ 144 bilhões em 2001 (Hausman \& Velasco 2003, p. 71). A crise argentina é emblemática porque a aplicação de políticas neoliberais é demonstravelmente conectada ao ambiente globalizante impulsionado pelos atores hegemônicos. Como propôs o economista Aldo Ferrer (2010, p. 387-388), que conceituou o período 1976-2001 como "hegemonia neoliberal" na Argentina: "O golpe militar [de 1976] teve lugar em cenário internacional no qual a conclusão do "período de ouro" deu lugar à substituição do paradigma keynesiano pelo neoliberal nos países centrais. Esses países não somente mudaram a orientação de suas políticas, mas voltaram a operar, em relação aos países da periferia, com base na velha premissa de que eles eram os depositários da racionalidade econômica e, como consequência, detinham as receitas adequadas para resolver os problemas dos países em desenvolvimento na América Latina, Ásia e África. Organizações multilaterais - FMI, BIRD e GATT - constituíram instrumentos para a construção de ordem global que era condicionada pelos interesses dos países centrais. A globalização, portanto, 
incluía dimensão ideológica, assim como condicionalidades que eram uma função da posição dominante dos países centrais".

No ambiente triunfalista do final da Guerra Fria, o plano de convertibilidade do presidente Carlos Menem, que vinculou um peso a um dólar, intensificou a integração da Argentina aos mercados financeiros globais (Bonelli 2004, p. 55), mas a insustentável convertibilidade reverteu em fuga de capitais e crescente endividamento. Como a dívida externa era a contrapartida para a fuga de capitais, ela não refletiu nenhuma melhora nos padrões de vida da população argentina, nem enriqueceu o Estado; ao contrário, o Estado vendeu ativos que somavam US\$ 20 bilhões somente no período 1990-1998 (Ferrer 2010, p. 413). O comprometimento da Argentina com o Consenso de Washington culminou no discurso triunfal de Menem no encontro anual do FMI e do Banco Mundial, em 4 de outubro de 1998. Esse evento único revela a dinâmica por trás da adoção das políticas do Consenso de Washington e a falência econômica, social e política sem precedentes que se abateu sobre a Argentina. Isso porque a apresentação oficial da Argentina como aluno modelo do Consenso de Washington (Blustein 2006, p. 4) teve lugar precisamente na conjuntura em que sinais inequívocos de desequilíbrio econômico generalizado tornaram-se visíveis por volta de 1998 (Tenembaum 2004, pp. 65-66).

Durante o governo De la Rúa (1999-2001), a incorporação dogmática da ideologia dominante impediu a consideração de alternativas que poderiam ter levado a um resultado diferente. A incorporação da receita neoliberal para lidar com crises levou a decisões (aumento de impostos, ajustamentos ortodoxos sequenciais, reforma da previdência, regra do déficit zero e empréstimo ruinosos), bem como a não decisões (controle de capitais, desvalorização, abandono da convertibilidade, moratória e mesmo um default antecipado) que desembocaram em um resultado final catastrófico. Os ministros do presidente De la Rúa indicavam a orientação do governo que tomou posse em dezembro de 1999 à medida que as posições-chave foram ocupadas por economistas liberais com inequívocas credenciais ortodoxas (Rapoport 2009, p. 871). Ricardo Lopéz Murphy - afiliado ao mais notório think tank neoliberal da Argentina, a Fundación de Investigaciones Económicas Latinoamericanas, foi designado ministro da defesa, Adalberto Rodríguez Giavarini assumiu o Ministério dos Negócios Estrangeiros e o antigo vice de Cavallo, Juan José Llach, foi nomeado ministro da educação.

A despeito do ambiente recessivo que levaria a uma queda de $3 \%$ do PIB em 1999, o novo ministro da economia José Luis Machinea anunciou abrangente pacote de aumento de impostos (impuestazo). Como observou o jornalista Marcelo Bonelli (2004, p. 89), "a aliança receberia um paciente terminal; entretanto, para curá-lo, cometeu um grave erro: aplicou o mesmo remédio que tinha levado a Argentina à unidade de terapia intensiva. Esse remédio iria matar o paciente". De la Rúa, com efeito, estava comprometido em manter a convertibilidade peso-dólar, bem como as medidas de austeridade apoiadas pelo FMI. Em pronunciamento televisivo no dia 23 de dezembro de 1999, De la Rúa asseverou que o maior inimigo da Argentina era o déficit fiscal, anunciando que o seu objetivo era obter o status de grau de investimento para o país. De la Rúa "não estava, na verdade, dirigindo-se ao público argentino, mas, sim, ao FMI" (idem, p. 76). O FMI condicionou novo acordo de stand-by a mais privatizações, controle federal sobre os déficits provinciais e, mais criticamente, uma ampla reforma trabalhista que acabou por desmantelar a coalizão governista. Isso porque o vice-presidente Carlos "Chacho" Álvarez, líder do segundo maior partido governista (Frepaso), deixou o governo depois que o 
presidente negou o seu apelo público por investigações sobre as denúncias generalizadas de suborno para a aprovação da reforma no Senado.

As negociações com o novo diretor-gerente do FMI, Horst Köhler, resultaram no empréstimo que veio a ser denominado blindaje, que envolvia reformas estruturais e mais privatizações. Depois de receber sinal verde do governo Clinton, Köhler aprovou o pacote, que foi anunciado em 18 de dezembro de 2000 (idem, p. 149-153). O blindaje, que seria frustrado pelo contexto doméstico turbulento e pela crise financeira que eclodiu na Turquia, assemelhava-se à linha de crédito de US\$ 50 bilhões que o Tesouro dos EUA disponibilizou ao México durante o efeito tequila. Os formuladores de política, entretanto, aprenderam as lições erradas da crise no México - assim como fariam no futuro com a crise na Argentina - ao culparem somente condições domésticas pela crise, mesmo que o México não tivesse feito qualquer desvio relevante das políticas associadas à ortodoxia econômica (Krugman 2009).

Uma solução possível teria sido a imposição de controles de capitais para reverter a vulnerabilidade do país à fuga de capitais. A não decisão argentina de aplicar controle de capitais, ou mesmo de considerá-los seriamente antes que fosse tarde demais em dezembro de 2001, é ainda mais surpreendente quando se constata que o Chile, outro notável seguidor de políticas neoliberais, aplicou-os com sucesso, não sem críticas por parte do Tesouro dos EUA e do FMI (Blustein 2003, p. 48). O grau de dogmatismo da oposição do FMI ao controle de capitais pode ser aferido por meio do argumento do diretor Claudio Loser, doutor pela Universidade de Chicago, de que, aplicados à crise argentina, os controles de capitais "representariam o pior dos sinais, equivalendo ao confisco" (Tenembaum 2004, p. 161). Esse tipo de raciocínio excluía sumariamente escolha de política plenamente legítima nas décadas em que prevaleceu o consenso keynesiano. Essa maneira de formular problemas era utilizada para descartar alternativas, como a desvalorização, largamente empregada na crise asiática em 1997, ou o abandono da paridade, que tirou o Brasil do abismo financeiro em 1999.

Depois da exoneração de José Luis Machinea, em março de 2001, o novo ministro Ricardo Lopéz Murphy, igualmente educado na Universidade de Chicago, propôs um ajuste ortodoxo que desencadeou uma série de pedidos de exoneração no governo. A rápida saída de Lopéz Murphy abriu caminho para o retorno do ministro da economia do governo Menem, Domingo Cavallo. Cavallo logrou obter poderes especiais do parlamento e negociou grande restruturação da dívida argentina, o megacanje de junho de 2001, que envolveu US\$ 30 bilhões e taxas de juros ruinosas. A Argentina teria um alívio de US\$ 12 bilhões nos juros até 2005, em troca de obrigações adicionais de US\$ 66 bilhões após aquele ano (Mussa 2002, p. 40). O megacanje realça o componente de fraude presente na crise argentina. Banqueiros de Wall Street produziram os relatórios mais otimistas sobre a Argentina entre 1999-2001, ao mesmo tempo em que ganharam cerca de US\$ 1 bilhão em taxas ao subscreverem os títulos da dívida do país, US\$ 100 milhões somente na operação do megacanje (Blustein 2006). Em vez de reestruturar a dívida em tais condições, a Argentina estaria em melhor situação se reconhecesse a impossibilidade de pagá-la, tomando medidas mais drásticas, como a declaração da moratória, a exemplo do México em 1982. Poderia, ainda, decretar um default antecipado, como fez a Rússia em 1998, sob intensa pressão para manter duras medidas de austeridade. Ainda que drásticas, essas medidas permitiriam à Argentina iniciar um novo ciclo. 
O movimento seguinte de Cavallo foi a regra do déficit zero, por meio da qual o governo federal abria mão legalmente do instrumento de usar déficits fiscais para fazer a economia crescer. A medida piorou a recessão econômica, aumentando o descontentamento social e agravando a fuga de capitais à medida que o país se aproximava do colapso. A regra do déficit zero de julho de 2001 levou ao paroxismo o conjunto de medidas de austeridade, pois, se o país já havia abdicado da política monetária com a convertibilidade, a nova regra efetivamente limitava a sua capacidade de fazer escolhas na área fiscal. O FMI condicionou um empréstimo de US\$ 8 bilhões, em agosto, à extensão da regra do déficit zero às províncias. É indicativo da resistência dos formuladores de política ao aprendizado que a Argentina tenha sido submetida ao mesmo pacote de medidas de austeridade imposto a países asiáticos como a Indonésia e a Tailândia, neste último caso, a recessão econômica não impediu o Fundo de pressionar por um arroxo fiscal que correspondeu a 3\% do PIB (Blustein 2003, pp. 75-76). Como sustentou o economista Barry Eicheengreen (2001) ao tempo da regra do déficit zero: "A regra do déficit zero somente piora o problema. Cortar gastos põe mais pressão deflacionária na economia. Receitas tributárias caem à medida que a economia se contrai, requerendo mais cortes em gastos públicos. Esses novos cortes levam a economia a se contrair ainda mais, em círculo vicioso. E cada corte de salários e aposentadorias no setor público aumenta a oposição política às políticas de austeridade do governo. Ao estender a regra do déficit zero às províncias, o programa aperta a corda no pescoço".

Em outubro de 2001, o FMI anunciou a decisão de sustar a liberação de recursos à Argentina, para o que a orientação antipacote de resgates do novo governo Bush foi instrumental. Em uma última e desesperada tentativa de conter corridas bancárias em dezembro, o governo introduziu de maneira atabalhoada controles de capitais e o corralito, que correspondia na prática à interposição de obstáculos físicos à retirada de recursos dos bancos. Com a Argentina à beira do caos e a violência nas ruas gerando protestos e saques, Fernando de la Rúa renunciou e fugiu espetacularmente da Casa Rosada em um helicóptero. A magnitude da crise política que se desenlaçou pode ser medida pelo fato de cinco presidentes terem assumido o posto em apenas 12 dias, até que o parlamento apontou Eduardo Duhalde como novo presidente no começo de 2002. Duhalde anunciou o fim da convertibilidade em meio a uma recessão sem precedentes e o maior default da história mundial.

A crença no Consenso de Washington tem sido tão arraigada que, mesmo após o colapso argentino, as obras mais influentes sobre as causas da crise argumentam que a bancarrota não foi criada pelas políticas neoliberais. Ao contrário, propugna-se que a crise teve lugar porque as referidas políticas não foram aplicadas com rigor suficiente. Nesse contexto, não surpreende que a sabedoria convencional sobre as causas da crise seja articulada por antigos membros do staff do FMI, que consideram que a crise foi causada pela incapacidade da Argentina em controlar o déficit fiscal. Ainda que o FMI tenha exercido pressão contínua em favor da austeridade, Michael Mussa, o economistachefe do FMI ao tempo do colapso em 2001, declarou que "se o Fundo cometeu erros importantes na Argentina", esses foram "principalmente pecados de omissão". Mussa sustenta que o FMI falhou ao não "pressionar muito mais as autoridades argentinas a ter uma política fiscal responsável" (Mussa 2002, pp. 4-5).

A sabedoria convencional sobre o colapso da Argentina é indicativa de que proeminentes acadêmicos que se tornaram formuladores de políticas em insti- 
${ }^{3}$ As traduções de língua estrangeira são de responsabilidade do autor. tuições sediadas em Washington engajam em exercício que Krugman (2002) definiu como "reescrever a história". A análise do orçamento argentino antes da crise revela não somente que os gastos primários estiveram constantes desde 1993, mas também que os déficits fiscais eram o resultado dos termos da privatização do sistema de aposentadorias, mais uma recomendação do FMI, e do pagamento de dívidas. De fato, o balanço primário, que exclui o pagamento de dívidas, aproximou-se de zero durante o período e, se as despesas temporárias com a reforma do sistema de aposentadorias forem desconsideradas, o governo federal da Argentina teria mostrado um crescimento do superávit de 1,3\% em 1995 a 3,3\% em 2000. Como propõem Hausman e Velasco (2003, p. 72), "a visão de que a Argentina era de alguma forma irresponsável na sua gestão fiscal e que essa pode ter sido uma das grandes causas da crise, e não apenas uma de suas consequências, tornou-se uma história dominante ex post" $^{3}$. Como argumentou Stiglitz (2002): "Um olhar mais atento ao orçamento demonstra o quão injusto é o retrato de prodigalidade argentina que tem sido amplamente traçado. Os números oficiais revelam um déficit de menos de 3 por cento do produto interno bruto, não é um número ultrajante. Relembremos que, em 1992, quando os Estados Unidos atravessavam recessão bastante mais suave que a atualmente observada na Argentina, o déficit do governo federal estava em 4,4 por cento do PIB. Uma economia em recessão normalmente incorre em déficit, porque as receitas fiscais despencam e a rede de gasto em seguridade social aumenta; e deveria mesmo haver déficit, uma vez que a sua eliminação joga a economia em recessão ainda maior. Mas mesmo 3 por cento é um número enganoso por causa da decisão da Argentina de privatizar o seu sistema de seguridade social nos anos 1990, uma ação encorajada pelo FMI. Com essa mudança, o dinheiro que estaria "dentro do orçamento" moveu-se para "fora". Nesses casos, mesmo se nada ocorrer com a economia a não ser privatizações, a posição orçamentária aparente piora grandemente porque o superávit do sistema de aposentadoria é retirado dos livros. Considere o seguinte: se tivéssemos privatizado o sistema de seguridade social em 1992, por exemplo, nosso déficit naquele ano teria ultrapassado os 8 por cento do PIB. Se a Argentina não tivesse privatizado, o seu orçamento de 2001 mostraria, na verdade, um superávit. A mudança na aposentadoria não criou um problema macroeconômico. No entanto, o FMI viu as coisas de uma forma diferente. Mesmo se pusermos isso de lado, no centro dos déficits orçamentários argentinos, não importa a forma por meio da qual alguém os avalie, não haveria prodigalidade, mas recessão econômica, que levou à queda na receita tributária".

\section{Princípios para uma Política Externa Brasileira Crítica}

Como as crises financeiras nos mercados emergentes no período posterior à Guerra Fria foram consideradas como tendo sido exclusivamente causadas pelos países em crise (Blustein 2003; Krugman 2009), que, supostamente, não teriam aplicado as práticas hegemônicas, a ideologia da liberalização e desregulamentação financeira sem limites pôde seguir seu curso até a eclosão da Grande Recessão em 2008. Krugman (2009) e Stiglitz (2010) têm demonstrado como a ideologia neoliberal e a criação de um novo sistema à margem dos bancos tradicionais estão por trás da crise financeira que abalou a economia global nos últimos anos. A debacle econômica que se seguiu à falência do Leman Brothers levou a crise para o centro da constelação de forças hegemônicas que impulsionaram a globalização das finanças. Governos implementaram pacotes de resgate na forma de gigantescos mecanismos de socialização das perdas, apenas para transformar crises financeiras em sucessivas crises de 
dívidas públicas, especialmente na Europa. Um formidável processo de reescrita da história foi posto em marcha, permitindo que os mesmos agentes econômicos que causaram a Grande Recessão agora apontem a prodigalidade de países europeus como causa da desaceleração econômica global. O enfoque sobre a imprevisibilidade de um setor financeiro fora de controle deu lugar, em apenas poucos anos, a ataques incessantes contra redes públicas de proteção social.

Como assevera Jahn (2005), embora os novos liberais invoquem o pensamento kantiano, suas prescrições divorciam-se, e mesmo invertem, as proposições do filósofo alemão. O novo liberalismo inverteu, de fato, o elemento emancipatório do liberalismo clássico para transformar-se em instrumento de ratificação do poder e da universalização das práticas hegemônicas em uma ordem global altamente assimétrica, que abre mercados onde os países desenvolvidos dispõem de vantagens competitivas, como finanças, e mantêm fechados segmentos nos quais os países em desenvolvimento têm possibilidades efetivas de competição, em especial, agricultura. A Grande Recessão precipitou a ascensão do Sul Global, em particular, países como o Brasil, a China e a Índia (PNUD 2013). Nesse contexto, o Brasil, como país de projeção crescente e defensor histórico da causa do desenvolvimento, encontra-se em posição privilegiada para avançar uma política externa crítica, que resgate o elemento emancipatório do liberalismo clássico, em contraposição ao liberalismo internacionalista contemporâneo. Enumeram-se, em seguida, três princípios para uma política externa brasileira crítica, que persiga noção de desenvolvimento entendida como liberdade (PNUD 1990; Sen 1999).

(i) O desenvolvimento das Nações condiciona-se à maior compreensão dos efeitos do poder no sistema internacional, uma vez que as condições que obstam o seu desenvolvimento encontram-se, em boa medida, na esfera internacional.

No ensaio "O que é o Iluminismo", Kant (1991c) vinculou o desenvolvimento dos seres humanos à maior compreensão das fontes externas de poder que impedem o preenchimento das suas potencialidades. De forma semelhante, os países menos poderosos somente poderão preencher suas potencialidades a partir do momento em que identificarem os obstáculos que se põem, em nível internacional, ao seu desenvolvimento. $\mathrm{O}$ traço mais marcante do novo liberalismo é a sua cegueira no que se refere às relações de poder no sistema internacional. Os novos liberais deixam de problematizar não somente as condições que permitiram a ascensão histórica dos Estados considerados "liberais", marcada por relações indisfarçadamente iliberais (Jahn 2009), mas também como as assimetrias da governança global contemporânea criam obstáculos ao desenvolvimento dos países menos poderosos. Em vez de abordarem os fardos que a governança global impõe aos países em desenvolvimento, os teóricos liberais culpam exclusivamente fatores domésticos pelas suas mazelas.

O Brasil, que exerce, historicamente, papel de liderança no mundo em desenvolvimento, dispõe de condições para avançar uma política externa crítica, que consagre noção do desenvolvimento como liberdade. A governança global hegemônica - FMI, Banco Mundial, G7, GATT - deu lugar à centralidade de novos fóruns, como o BRICS, o G20 e a OMC, em que o Brasil pode exercer papel ativo, ou mesmo de protagonismo. Uma política externa crítica trabalharia para intensificar o processo de reforma da governança global, com maior equilíbrio no mecanismo decisório do FMI e do Banco Mundial. No âmbito do BRICS, destaquem-se iniciativas como o Arranjo Contingente de Reservas e o 
novo Banco do Desenvolvimento, que permitirá a países menos abastados obterem financiamento para projetos voltados ao desenvolvimento. O Brasil poderá empreender esforços para garantir que, em lugar de constituírem parte de nova pretensão hegemônica, os instrumentos negociados no BRICS auxiliem outros países a trilharem seus próprios caminhos rumo ao desenvolvimento.

(ii) As nações devem ser livres para perseguir seus próprios caminhos rumo ao desenvolvimento, aplicando as políticas que considerarem necessárias a esse fim, resguardados os direitos de outras nações de agir da mesma forma.

Da mesma forma que os seres humanos não podem desenvolver-se sob a tutela alheia, não se pode conceber forma de desenvolvimento nacional dirigido por atores ou instituições hegemônicos externos. A liberdade na formulação de políticas é uma condição necessária, embora não suficiente, para o verdadeiro desenvolvimento das nações. Ainda que decisões tomadas por países em desenvolvimento por vezes causem desapontamento do ponto de vista da liberdade e prosperidade dos seus próprios cidadãos, mais vale conviver com eventuais erros das nações menos desenvolvidas do que com a certeza de que continuarão a desempenhar papel subordinado em ambiente estruturalmente voltado à satisfação dos interesses de potências hegemônicas. Kant propõe, na sétima tese do ensaio "Ideia de uma história universal de um ponto de vista cosmopolita", que "o problema de estabelecer uma constituição civil perfeita é subordinado ao problema de uma relação governada pelo Direito com outros Estados, e não pode ser resolvido até que este último seja resolvido" (Kant 1991c, p. 47). Cabe ressaltar que, para Kant (idem), a moral engloba o Direito, de forma que relações governadas pelo Direito pressupõem relações morais ou seja, em suas interações, os povos tratam-se como fins em si mesmos, não como meios para a realização dos seus próprios interesses.

A liberalização financeira pode ser benéfica em termos econômicos, mas há que se investigarem seus efeitos em termos de desenvolvimento para a tomada de decisão quanto ao grau de abertura de capitais. Nas últimas décadas, a política de abertura financeira das nações em desenvolvimento variou de acordo com interesses externos. Invertendo-se a máxima moral kantiana, as nações mais pobres têm sido tratadas mais como objetos para a satisfação dos interesses dos poderosos do que como fins em si mesmas. No ambiente atual de crise, devem ser retomados elementos da orientação econômica keynesiana, conferindo-se maior importância à economia real. O Brasil deve continuar a enfatizar o papel do crescimento econômico e da manutenção de altos níveis de emprego para que se leve a termo a Grande Recessão, ao contrário das medidas de excessiva austeridade que tendem a agravar a crise iniciada em 2008.

(iii) Para que o comércio internacional promova o desenvolvimento das nações, estas dele devem participar voluntariamente; ademais, o intercâmbio deve beneficiar todas as nações envolvidas, em especial as menos abastadas.

Ainda que Kant acreditasse nos efeitos pacificadores do comércio, ele observou, no ensaio sobre a paz perpétua, que as relações comerciais das potências imperialistas com países mais fracos transcorriam sob o signo de "chocante injustiça" (Kant 1991a, p. 106). Atualmente, os novos liberais, ao proporem que as instituições internacionais invariavelmente trazem ganhos a todos os atores envolvidos, deixam de problematizar como os países menos poderosos são forçados a participar de arranjos comerciais que lhe trazem perdas absolutas. O Acordo que Estabelece a OMC exemplifica paradigmaticamente a codificação jurídica de normas assimétricas, pois mercados foram 
abertos de forma seletiva e imperial (Steinberg 2002), trazendo-se perdas absolutas a países de menor desenvolvimento relativo (Stiglitz 2003; Charltone \& Stiglitz 2005; Finger 2007). Dadas as assimetrias do regime de comércio, não surpreende que protestos antiglobalização em todo o mundo tenham sido iniciados no contexto de uma Conferência Ministerial da OMC, realizada em Seattle, em 1999. Como sintetizou Jahn (2005, p. 192): "O comércio e outras formas de interação transnacional apenas podem ser meios para um fim moral se realizados voluntariamente por todas as partes [...] interesses privados no interior de Estados capitalistas liberais continuam a perseguir a abertura de mercados no exterior, e eles continuam a aliciar o apoio dos seus governos, por meio de arranjos bilaterais e multilaterais - a ajuda condicionada, o Fundo Monetário Internacional e a Organização Mundial do Comércio. Embora as tratativas sejam formalmente 'voluntárias', à luz da desesperada dependência econômica de muitos países em desenvolvimento, elas são, para todos os efeitos, 'impostas'".

Como resposta aos apelos por maior equidade, lançou-se, em 2001, a Agenda do Desenvolvimento de Doha. Após anos de estagnação no âmbito da OMC, celebrou-se, na Conferência Ministerial de Bali, em dezembro de 2013, o acordo de facilitação de comércio, o primeiro desde a criação da OMC. As assimetrias do Acordo que Estabelece a OMC não devem levar ao abandono da via multilateral; ao contrário, o Brasil deve buscar a reforma do arcabouço normativo da organização na Rodada Doha, pois somente negociações multilaterais podem trazer ganhos mais amplos aos países em desenvolvimento, em particular, aqueles de menor desenvolvimento relativo, que não dispõem de condições para barganhar vantagens bilateralmente. Além de abrangente liberalização agrícola e em produtos primários, com a eliminação de todas as formas de subsídios às exportações, uma verdadeira rodada para 0 desenvolvimento deve reformar o TRIPS para reequilibrar a relação entre exportadores e importadores de propriedade intelectual. Deve-se, ainda, proverse maior assistência aos países menos poderosos para que o sistema de consenso não funcione como instância de "hipocrisia organizada" (Steinberg 2002) e, também, para que os países mais pobres participem efetivamente do mecanismo de solução de controvérsias. O momentum atual criado no âmbito da OMC deve ser aproveitado para que se logrem progressos no longo caminho que se deve trilhar para estabelecer maior equilíbrio nos seus acordos originais.

Igor Abdalla (igabdalla@yahoo.com.br) é PhD em Ciências Políticas e Sociais pelo Instituto Universitário Europeu (Florença, Itália) e diplomata de carreira no Ministério de Relações Exteriores do Brasil (MRE). As opiniões expressas no artigo são exclusivas do autor e não guardam relação com a sua filiação institucional.

\section{Referências}

Alston, P. 1997. The Myopia of the Handmaidens: International lawyers and globalization. European Journal of International Law, 8(3), pp. 435-448.

Blustein, P. 2003. The Chastening: Inside the crisis that rocked the global financial system and humbled the IMF. New York: Public Affairs.

2006. And the Money Kept Rolling In (and Out): The World Bank, Wall Street, the IMF and the Bankrupting of Argentina. New York: Public Affairs.

Bonelli, M. 2004. Un país en deuda: la Argentina y su imposible relación con el FMI. Buenos Aires: Grupo Planeta.

Charlton, A.; Stiglitz, J. 2005. Fair Trade for All: How trade can promote development. Oxford: Oxford University Press.

Cox, R. 1981. Social Forces, States and World Orders: Beyond International Relations Theory. Millennium - Journal of International Studies, 10(2), pp. 126-155.

. 1983. Gramsci, Hegemony and International Relations: An essay in method. Milennium - Journal of International Studies, 12(2), pp. 162-175. 
Davenport, M.; Page, S. 1994. World Trade Reform: Do developing countries gain or lose? London: Overseas Development Institute.

Doyle, M. 1983. Kant, Liberal Legacies, and Foreign Affairs. Philosophy and Public Affairs, 12(3), pp. 205-235.

Ferrer, A. 2010. La economía argentina: desde sus orígenes hasta principios del Siglo XXI. Buenos Aires: Fondo de Cultura Económica.

Finnemore, M.; Toope, S. 2001. Alternatives to 'Legalization': Richer views of Law and Politics. International Organization, 55(3), pp. 743-758.

Finger, M.; Schuler, P. 2000. Implementation of Uruguay Round Commitments: The Development Challenge. World Economy, 24(4), pp. 511-525.

Finger, M. 2007. Implementation and Imbalance: Dealing with hangover from the Uruguay Round. Oxford Review of Economic Policy, 23(3), pp. 440-460.

Friedman, M.; Schwartz, A. 1963. A Monetary History of the United States, 1867-1960. Princeton: Princeton University Press.

Gill, S.; Law, D. 1989. Global Hegemony and the Structural Power of Capital. International Studies Quarterly, 33(4), pp. 475-499.

. Globalisation, Market Civilisation, and Disciplinary Neoliberalism. Millennium - Journal of International Studies,24 (3), pp. 399-423.

Goldstein, J.; Martin, L. 2000. Legalization, Trade Liberalization, and Domestic Politics: A cautionary note. International Organization, 54(3), pp. 603-632.

Harrison, G.; Rutherford, T.; Tarr, D. 1995. Quantifying the Uruguay Round. In W. Martin; A. Winters, eds. The Uruguay Round and the Developing Economies. Washington, D.C.: World Bank.

Hayek, F.A. 1944. The Road to Serfdom. London: Routledge.

Hausman, R.; Velasco, A. 2003. Hard Money's Soft Underbelly: Understanding the Argentine Crisis. In S. Collins; D. Rodrik, eds. Brookings Trade Forum 2002. Washington, D.C.: Brookings Institution Press.

Helleiner, E. 1994. States and the Emergence of Global Finance: From Bretton Woods to the 1990s. Ithaca: Cornell University Press.

Jahn, B. 2005. Kant, Mill and Illiberal Legacies in International Affairs. International Organization, 59(1), pp. 177-207. 2009. Liberal Internationalism: From ideology to empirical theory - and back again. International Theory, 1(3), pp. 409-438.

Kant, I. 1991a. Perpetual Peace: A philosophical sketch. In H. Reiss, ed. Kant: Political Writings. Cambridge: Cambridge University Press.

. 1991b. Idea for a Universal History with a Cosmopolitan Purpose. In H. Reiss, ed. Kant: Political Writings. Cambridge: Cambridge University Press.

. 1991c. An Answer to the Question: "What is the Enlightenment?" In H. Reiss, ed. Kant: Political Writings. Cambridge: Cambridge University Press.

Kennedy, D. 1999. The Disciplines of International Law and Policy. Leiden Journal of International Law, 12(1), pp. 9-133. 2001. The Politics of the Invisible College: International Governance and the Politics of Expertise. European Human Rights Law Review, 5, pp. 463-497. 2004. The Dark Sides of Virtue: Reassessing International Humanitarianism. Princeton: Princeton University Press.

Keohane, R. 1984. After Hegemony: Cooperation and discord in the world political economy. Princeton: Princeton University Press.

2005. After Hegemony: Cooperation and discord in the world political economy. Princeton: Princeton University Press.

Koskenniemi, M. 2001. Gentle Civilizer of Nations: The rise and the fall of International Law. Port Chester: Cambridge University Press.

Kratochwil, F. 2010. How (Il)liberal is the Liberal Theory of Law? Some Critical Remarks on Slaughter's Approach. Comparative Sociology, 9(1), pp. 120-145.

Kratochwil, F.; Ruggie, J.G. 1986. International Organization: A state of the art on an art of the State. International Organization, 40(4), pp. 753-775.

Krugman, P. 2002. Crying with Argentina. The New York Times, 1.Jan. 2009. The Return of Depression Economics and the Crisis of 2008. Nova York: W.W. Norton.

Maskus, K. 2000. Intellectual Property Issues for the New Round. In J. Schott, ed. The WTO after Seattle. Washington, D.C.: Institute for International Economics.

Medina de Souza, I. 2011. O Liberalismo Interdisciplinar DI/RI no Pós-Guerra Fria: uma análise crítica. Revista Ética e Filosofia Política, 13(2), pp. 25-44.

2013. An Offer Developing Countries Could Not Refuse: How powerful states created the World Trade Organization. Journal of International Relations and Development, August. Doi:10.1057/jird.2013.18.

Moravcsik, A. 1997. Taking Preferences Seriously: A Liberal Theory of International Politics. International Organization, 51 (4), pp. 513-553.

. 1998. The Choice for Europe: Social purpose and state power from Messina to Maastricht. New York: Cornell University Press.

. 2008. The New Liberalism. In C. Reus-Smit; D. Snidal, eds. The Oxford Handbook of International Relations. Oxford: Oxford University Press. 
Mussa, M. 2002. Argentina and the Fund: From triumph to tragedy. Washington, D.C.: Institute for International Economics. Petersmann, E.U. 1997. The Gatt/Wto Dispute Settlement System: International Law, International Organizations and Dispute Settlement. London: Kluwer Law International.

Rapoport, M. 2009. Historia económica, política y social de la Argentina (1880-2003). Buenos Aires: Emecé.

Rawls, J. 1999. The Law of Peoples. Cambridge, MA: Harvard University Press.

Ruggie, J.G. 1982. International Regimes, Transactions, and Change: Embedded liberalism in the postwar economic system. International Organization, 36(2), pp. 379-415.

Sen, A. 1999. Development as Freedom. Oxford: Oxford University Press.

Slaughter, A.M. 1993. International Law and International Relations Theory: A dual agenda. American Journal of International Law, 87, pp. 205-239.

1995. International Law in a World of Liberal States. European Journal of International Law, 6, pp. 503-538.

1997. The Real New World Order. Foreign Affairs, 76(5), pp. 183-197.

2000. International Law and International Relations - Millennial Lectures. Hague: Hague Academy of International Law.

2004. A New World Order. Princeton: Princeton University Press.

Smith, S. 2004. Singing Our World into Existence: International Relations Theory and September 11. International Studies Quarterly, 48(3), pp. 499-515.

Stein, A. 1990. Why Nations Cooperate: Circumstance and choice in International Relations. London: Cornell University Press.

Steinberg, R. 2002. In the Shadow of Law or Power? Consensus-Based Bargaining and Outcomes in the GATT/WTO. International Organization, 56(2), pp. 339-374.

Stiglitz, J. 2002. Argentina, Short-Changed: Why the nation that followed the rules fell to pieces. Washington Post, 12.May. 2003. Globalization and its Discontents. New York: W.W. Norton.

2010. Freefall: America, Free Markets, and the Sinking of the World Economy. New York: W.W. Norton.

Strange, S. 1988. States and Markets. London: Pinter Publishers.

Tenembaum, E. 2004. Enemigos: Argentina y el FMI: la apasionante discusión entre un periodista y uno de los hombres clave del Fondo en los noventa. Buenos Aires: Grupo Editorial Norma.

Williamson, J. 1998. Globalization: The concept, causes and consequences. Keynote address to the Congress of the Sri Lankan Association for the Advancement of Science. Peterson Institute for International Economics. Disponível em: http://www.iie.com/publications/papers/paper.cfm?ResearchID=330. Acesso em: 23.maio.2014.

\title{
Outras fontes
}

- PNUD. 2013. Human Development Report. New York: PNUD.

\begin{abstract}
The article analyzes the emergence, in recent decades, of a new international liberalism of technocratic nature, which contrasts with the classical liberalism created by critical philosopher Immanuel Kant. The new liberalism, which coincides with the process of financial globalization, reverses the emancipatory element of Kantian liberalism to present itself as an instance of power ratification. As a result, the new liberals are incapable of critically analyzing events such as the Great Recession.I propose principles for a critical foreign policy for Brazil, in contrast to the new technocratic liberalis. In empirical terms, I investigate the evolution of the globalization of finance from the perspective of power, focusing on the financial crises in the developing world and the 2008 Great Recession. I argue that 1) the new liberalism contradicts the classical liberalism; 2) the new liberalism legitimates interests of hegemonic actors towards financial liberalization and unrestrained deregulation, which are the roots of the Great Recession, 3) Brazilian foreign policy must bring back elements from classical liberalism in the context of crisis generated by the Great Recession.
\end{abstract}

KEYWORDS: international liberalism; critical theory; globalization; Brazilian foreign policy; crisis of 2008. 